\title{
Genetic variation and selection in the major histocompatibility complex Class II gene in the Guizhou pony
}

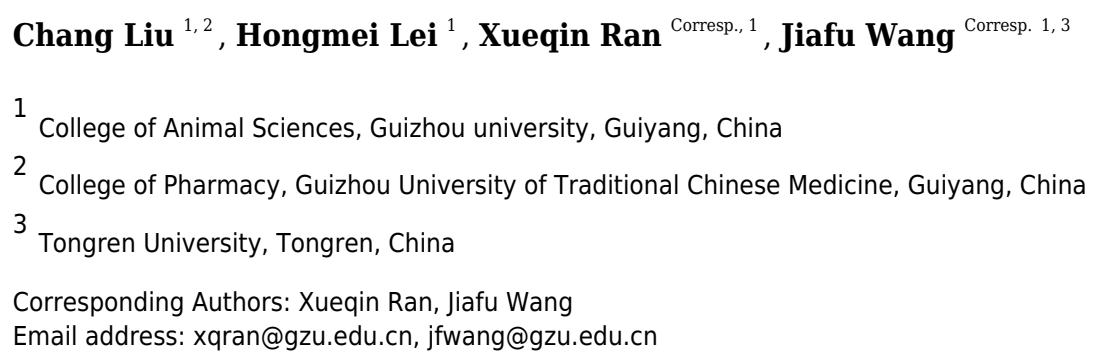

The Guizhou pony (GZP) is an indigenous species of equid found in the mountains of the Guizhou province in southwest China. We selected four regions of the equine leukocyte antigen (ELA), including $D Q A, D R A, D Q B$, and $D R B$, and used them to assess the diversity of the major histocompatibility complex $(\mathrm{MHC})$ class II gene using direct sequencing technology. DRA had the lowest $d_{N} / d_{\mathrm{S}}$ ratio (0.560) compared with the other three loci, indicating that $D R A$ was conserved and could be conserved after undergoing selective processes. Nine $D Q A$, five $D Q B$, nine $D R A$, and seven $D R B$ codons were under significant positive selection at the antigen binding sites (ABS), suggesting that the selected residues in ABS may play a significant role in the innate immune system of the GZP. Two GZP alleles were shared with Przewalski's horse, and six older GZP haplotypes had a better relationship with other horse species by one or two mutational steps, indicating that the GZP may be a natural ancient variety of equid. The specific diversity of ABS and the numbers of unique haplotypes in the evolutionary process affords this species a better genetic fitness and ability to adapt to the native environment. 
1 Genetic variation and selection in the major histocompatibility complex Class II gene in the Guizhou

2 pony

3 Chang Liu ${ }^{1,2}$, Hongmei Lei ${ }^{1}$, Xueqin Ran ${ }^{1 *}$, JiafuWang ${ }^{1,3 *}$

$4 \quad{ }^{1}$ College of Animal Sciences, Guizhou University, Guiyang, China;

$5 \quad{ }^{2}$ College of Pharmacy, Guizhou University of Traditional Chinese Medicine, Guiyang, China;

$6 \quad{ }^{3}$ Tongren University, Tongren, China.

7 Corresponding author Email: xqran@gzu.edu.cn (X. Ran), jfwang@gzu.edu.cn (J. Wang)

9 ABSTRACT

10 The Guizhou pony (GZP) is an indigenous species of equid found in the mountains of the Guizhou province in 11 southwest China. We selected four regions of the equine leukocyte antigen (ELA), including $D Q A, D R A, D Q B$, 12 and $D R B$, and used them to assess the diversity of the major histocompatibility complex (MHC) class II gene using direct sequencing technology. DRA had the lowest $d_{\mathrm{N}} / d_{\mathrm{S}}$ ratio $(0.560)$ compared with the other three loci, indicating that $D R A$ was conserved and could be conserved after undergoing selective processes. Nine $D Q A$, five $D Q B$, nine $D R A$, and seven $D R B$ codons were under significant positive selection at the antigen binding sites (ABS), suggesting that the selected residues in ABS may play a significant role in the innate immune system of the GZP. Two GZP alleles were shared with Przewalski's horse, and six older GZP haplotypes had a better relationship with other horse species by one or two mutational steps, indicating that the GZP may be a natural ancient variety of equid. The specific diversity of ABS and the numbers of unique haplotypes in the evolutionary process affords this species a better genetic fitness and ability to adapt to the native environment.

\section{INTRODUCTION}

The major histocompatibility complex (MHC) genes play a major role in vertebrate immune systems and have a high degree of genetic diversity associated with the adaptive immune response and evolution (Lian et al., 2017; Kamath et al., 2011). The MHC system is divided into class I and class II, which are key parts of the immune system (Hughes et al.,1988). The MHC class II genes are highly polymorphic parts of the immune response that 
act by presenting extracellular antigens to T lymphocytes. These molecules are heterodimers with $\alpha$ and $\beta$ chains encoded by A and B genes. The polymorphic sites of the class II genes are typically located at exon 2, which codes for the first extracellular domain or the antigen binding sites (ABS). The exon 2 codes for a section of the pocket of the MHC molecule. The ABS mainly encoded the second exon of the MHC class II gene, have more variation than the neighboring regions in this sequence (Li et al., 2014), indicating that ABS variation may help to determine the rates of evolution across the MHC (Hughes et al., 1995). Previous studies have shown that exon 2 of MHC class II genes had the most polymorphisms and encoded the $\alpha$ and $\beta$ domains principally responsible for peptide binding (O'Connor et al., 2007). The polymorphism of the MHC loci is commonly associated with different susceptibilities to infectious diseases (Hill et al., 2001), especially in sheep (Paterson et al., 1998), mice (Meyer-Lucht et al., 2005), voles (Kloch et al., 2010) and lemurs (Schad et al., 2005). The equine MHC class II loci may assist in determining the host response to pathogens encountered by the horse (Miller et al., 2017). MHC variants play key roles in mate preference, kin recognition, and maternal-fetal interactions (Edwards et al., 1998; Bernatchez et al., 2003; Piertney et al., 2006). The diverse functions and characteristics of MHC molecules is reflected in the evolutionary and adaptive processes within and between populations (Sommer et al., 2005).

The mechanisms of negative frequency-dependent selection (NFDS) and over-dominant selection have been well-studied in MHC genes. NFDS maintains intraspecific diversity and may interact with population density (Levitan et al., 2006; Meyer et al., 2007). Over-dominant selection can maintain genetic polymorphisms in populations (Takahata et al., 1990). Correlative and experimental support for the negative frequency-dependent selection of MHC genes has been shown in humans (Trachtenberg et al., 2003), reed warblers (Westerdahl et al., 2004), mice (Kubinak et al., 2012), sticklebacks (Eizaguirre et al., 2012; Bolnick and Stutz, 2017) and guppies (Phillips et al., 2018). There are a number of examples of asymmetric over-dominant selection in populations found in the wild and in the laboratory (Landry et al., 2001; Richman et al., 2001; Lenz et al., 2009; Schwensow et al., 2010; Lenz et al., 2013). These results are supported by several computer-based binding prediction studies (Lenz, 2011; Lau et al., 2015; Buhler et al., 2016; Pierini and Lenz, 2018). Three primary sources of evidence currently support the idea of balancing selection: (i) elevated levels of polymorphisms, (ii) the rates of nonsynonymous $\left(d_{\mathrm{N}}\right)$ to synonymous $\left(d_{\mathrm{S}}\right)$ nucleotide substitutions (Hughes et al., 1988; Hughes et al., 1989), and (iii) trans-species polymorphisms with alleles among species (Klein et al., 1993). The $d_{\mathrm{N}} / d_{\mathrm{S}}$ ratio 
53 is frequently used to measure selective pressure on genes (Yang et al., 2000), and more specifically, the markedly 54 different rates of evolution across the MHC genes (Hughes et al., 1995). Site-specific methods have found 55 elevated $d_{\mathrm{N}} / d_{\mathrm{S}}$ ratios at ABS, suggesting substantially different rates of evolution across the MHC. MHC variation within species and among species has proven to be useful in determining the historical patterns of selection in various mammals (Cutrera et al., 2007).

In the family Equidae, the horse MHC class II gene, also known as equine leukocyte antigen (ELA) class

II, is located on the short arm of chromosome 20q14-q22 (Mäkinen et al., 1989; Ansari et al., 1988). It contains the $D Q A, D Q B, D R A$, and $D R B$ genes. The $D Q A$ and $D R A$ genes encode for the $\alpha$-chain of ELA class II molecules, and the polymorphisms of the $D Q A$ and $D R A$ genes have been determined in European equids (Luís et al., 2005; Janova et al., 2009; Kamath et al., 2011). The $D Q B$ and $D R B$ genes encode the $\beta$-chain of the ELA class II complex, and high levels of $D R B$ and $D Q B$ polymorphisms have been reported in Arabian and European horses (Fraser et al., 1996; Mashima et al., 2003). Previous reports indicated that exon 2 of the ELA class II gene is genetically diverse among horse populations (Kamath et al., 2011). We examined the sequence variation in the second exon to determine the selective pressures and evolutionary path for the Guizhou pony.

The Guizhou pony is an indigenous species that was found in the Guizhou province during the Warring States Period (475-221 B.C.) in Ancient China. It is one of five Chinese pony species and has a body height of only 1.1 meters (10-11 hands). The mtDNA/SSR polymorphism has been determined in several pony populations derived from native Irish, Canadian, and Chinese breeds using mtDNA/SSR markers (McGahern et al. 2006; Prystupa et al. 2012). We sought to analyze the variation in the MHC II exon 2 of the $D Q A, D R A, D Q B$, and $D R B$ regions and their relationship with the selection and evolution in the GZP.

\section{MATERIAL AND METHODS}

\section{Animal collection and DNA isolation}

A total of 50 blood samples were collected from GZP in Ziyun County, Anshun, Guizhou Province, China. All ponies used in our study were 4 to 8 years old. All animal procedures were approved by the Institutional Animal

Care and Use Committee of Guizhou University (Approval number EAE-GZU-2018-P007). The GZP were randomly selected and were all well-developed and in good health, with heights ranging from 102 to $118 \mathrm{~cm}$ and weights between 210 to $265 \mathrm{~kg}$. Blood samples were collected from the jugular vein and were kept in EDTA 
80

$\mathrm{Na}$ 2. All samples were stored at $-20^{\circ} \mathrm{C}$ until DNA extraction. Genomic DNA was extracted from blood samples using the SQ Blood DNA Kit (OMEGA, USA). The nucleic acid concentration of the extracted genomic DNA was calculated by determining OD260/OD280, and detected by $0.7 \%$ agarose gel electrophoresis.

\section{PCR amplification, cloning, and sequencing}

The exon 2 regions of the $E L A-D Q A, D Q B, D R A$, and $D R B$ genes were amplified from genomic DNA using PCR with specific primers. We amplified $246 \mathrm{bp}$ of the $D R A$ using the equid-specific primers $D R A-\mathrm{F}$ and $D R A-\mathrm{R}$ (Albright Fraser et al., 1996), 246 bp of the $D Q A$ using the primers $D Q A-\mathrm{F}$ and $D Q A$-R (Fraser et al., 1998), 276 bp of the $D R B$ using the primers $D R B$-F and $D R B$-R (Fraser et al., 1996), and 230 bp of the $D Q B$ using the primers $D Q B-\mathrm{F}$ and $D Q B-\mathrm{R}$ (Mashima et al., 2003). All primers were synthesized by the Bio-Engineering Company (Shanghai, China) (Table 1). The total PCR volume was $20 \mu \mathrm{L}$, and contained $10 \mu \mathrm{L}$ of $2 \times$ PCR Mixture (0.1 U Taq Plus Polymerase/ $\mu \mathrm{L}, 500 \mu \mathrm{M}$ dNTP each, $20 \mathrm{mM}$ Tris-HCl (pH8.3), $100 \mathrm{mM} \mathrm{KCl,} 3 \mathrm{mM}$ $\left.\mathrm{MgCl}_{2}\right), 0.4 \mu \mathrm{L}$ of upstream/downstream primers $(10 \mu \mathrm{mol} / \mathrm{L})$, and $1 \mu \mathrm{L}$ templates. PCR amplification was carried out with initial denaturation at $95^{\circ} \mathrm{C}$ for $5 \mathrm{~min}$, followed by 30 cycles $\left(95^{\circ} \mathrm{C}\right.$ for $30 \mathrm{~s}, 58^{\circ} \mathrm{C}$ for $30 \mathrm{~s}$, and $72{ }^{\circ} \mathrm{C}$ for $30 \mathrm{~s}$ ), and a final extension at $72^{\circ} \mathrm{C}$ for $10 \mathrm{~min}$. PCR products were extracted and purified using the Gel Extraction Kit (OMEGA, USA), and were ligated into pGEM®-T vectors and transformed into $E$. coli competent cells. Twenty positive clones of each sample were removed with a sterile toothpick and were detected using the Sanger sequencing method (Invitrogen, China). Alleles were confirmed if the same allele was observed in at least two different individuals.

\section{DNA sequence polymorphism analysis}

The base composition of the $D R A, D R B, D Q A$ and $D Q B$ genes was analyzed using MEGA7 software (Kumar et al., 2016). Standard descriptive diversity indices for each locus within the GZP were calculated using MEGA7 software, including the variable sites (V), parsim-info sites $(\mathrm{P})$, singleton sites $(\mathrm{S})$, and the transition/transversion bias ratio (R). It was important to ascertain whether the variability was uniformly distributed or was confined to small segments of the variable regions when determining the nature of the variable region. The Wu-Kabat variability index was calculated using the formula by $\mathrm{Wu}$ and Kabat (Wu et al., 1970) with respect to amino acids at peptide-binding pockets. The variation of amino acids was calculated by the mutation rate (variability $=$ 
number of different amino acids at a certain position/frequency of the most common amino acids at this position) (Wu et al., 1970). Selection was estimated using MEGA7 software in terms of the relative rates of nonsynonymous $\left(d_{\mathrm{N}}\right)$ and synonymous $\left(d_{\mathrm{S}}\right)$ mutations, according to Nei and Gojobori's method with the Jukes and Cantor (JC) correction (Nei et al., 1986). The selection Z-Test $(\mathrm{P}<0.05)$ was performed for all sites under the null hypothesis of neutrality $\left(d_{\mathrm{N}}=d_{S}\right)$ and the alternative hypotheses of non-neutrality $\left(d_{\mathrm{N}} \neq d_{\mathrm{S}}\right)$, positive selection $\left(d_{\mathrm{N}}>d_{\mathrm{S}}\right)$, and purifying selection $\left(d_{\mathrm{N}}<d_{\mathrm{S}}\right)$.

\section{Site-specific selection analyses and protein 3D structure analysis}

We estimated the nonsynonymous and synonymous substitutions in the overall domain, ABS, and non-ABS for the $D Q A, D Q B, D R A$ and $D R B$ alleles. We assessed the positive selection using CodeML subroutine in the PAML program (Yang, 2007), which was more sensitive than other methods for assessing selection at the molecular level (Anisimova et al., 2001). The PAML program used the maximum likelihood estimation to examine heterogeneity in rates of $\omega=d_{\mathrm{N}} / d_{\mathrm{S}}$ among codons (Bielawski et al., 2003). The PAML program was able to better detect the molecular evidence of selection compared to other programs (Anisimova et al., 2003). We assessed heterogeneity in $\omega(\omega<1$ : purifying selection, $\omega=1$ : neutral evolution, $\omega>1$ : positive selection) across the four alleles $(D Q A, D Q B, D R A$ and $D R B)$ to identify codons under positive selection. The observed $\omega$ value followed six models in PAML: M0 (one ratio, average $\omega$ across all sites), M1a (nearly neutral), M2a (positive selection), M3 (discrete), M7 (beta), and M8 (beta and omega) (Yang et al., 2000). We used the online SWISS-MODEL program (Biasini et al., 2014; Waterhouse et al., 2018) (https://swissmodel.expasy.org/interactive) to make predictions about the $D Q A, D Q B, D R A$ and $D R B$ protein structures.

\section{Phylogenetic allele networks}

We constructed a median-joining haplotype network to infer the phylogenetic relationships among the sequence haplotypes (Bandelt et al., 1999) using the maximum parsimony in Network 4.6 .1 (http://www.fluxusengineering.com/sharenet.htm). The haplotype median networks of $D Q A, D Q B, D R A$ and $D R B$ between GZP and known horse species (Eqca, E.callabus; Eqpr, E.przewalski; Eqki, E.kiang; Eqgr, E.grevyi; Eqas, E.asinus; Eqbu, E.burchelli; Eqze, E.zebra; Eqhe, E.hemionus) from GenBank were plotted using NetWork 4.6. The frequency information and population proportion of the alleles were incorporated into the visualization of the 
133

134

135

136

137

138

139

140

141

142

143

144

145

146

147

148

149

150

151

152

153

154

155

156

157

158

159 network. Sequences from the horse, including E. callabus, E. przewalskii, E. burchellii, E. asinus, were incorporated to evaluate the distance from the Guizhou pony's haplotypes (Table 2).

\section{RESULTS}

\section{Analysis of nucleotide diversity}

184 alleles were identified from 1000 sequencing clones, with 118 effective alleles selected from the total. Of the 118 alleles, there were 18 novel $D Q A$ alleles (GenBank accession number: MT304744 - MT304761), 38 new $D Q B$ alleles (MT304705 - MT304743), 22 new DRA alleles (MT304762 - MT304783) and 28 new DRB alleles (MT304784 - MT304811) (Table S1). The alignment results are listed in Table S1 for the effective alleles from $D Q A, D Q B, D R A, D R B$ and the sequences of JQ254059, AF034122, AJ575295, and AF144564. A considerable sequence diversity within the genus was revealed based on the $D Q A, D Q B, D R B$ alignment results. The nucleotide diversity in $D R A$ was much lower than in $D Q A / B$ and $D R B$ in GZP, which is comparable with the level of nucleotide diversity in DRA from other species in the Equus genus (Kamath et al., 2011). Within the GZP, the genetic diversity was much higher in $D Q A, D Q B$, and $D R B$ than in $D R A$ and the ratio (variable sites/length) was the lowest at the DRA locus (15.04\%) and highest at the DQB locus (46.08\%).

\section{Analysis of nucleotide compositions}

The GC contents of $D Q B$ and $D R B$ were higher than those of $D Q A$ and $D R A$ (Table S2). The content of $\mathrm{G}+\mathrm{C}$ (48.10\%) was slightly lower than that of $\mathrm{A}+\mathrm{T}(51.90 \%)$ at $D Q A$, and the content of $\mathrm{G}+\mathrm{C}(48.10 \%)$ was lower than that of $\mathrm{A}+\mathrm{T}(51.90 \%)$ at $D R A$, which revealed that $D Q A$ and $D R A$ had lower GC percentages. However, the base composition of $\mathrm{G}+\mathrm{C}(64.20 \%)$ was higher than that of $\mathrm{A}+\mathrm{T}(35.80 \%)$ in $D Q B$ alleles, and the base composition of $\mathrm{G}+\mathrm{C}(61.90 \%)$ was more than that of $\mathrm{A}+\mathrm{T}(38.10 \%)$ in $\mathrm{DRB}$ alleles, revealing that $D Q B$ and $D R B$ had a higher GC content. The R (transitions/transversions) was 1.357 and 2.241 in the $D Q A$ and $D R A$ alleles, respectively. However, there was an R of 0.778 and 0.573 in the $D Q B$ and $D R B$ alleles, respectively. Our results revealed that the $D R A$ locus was more well-conserved than the other loci.

\section{The amino acid composition analyses}

We determined that the exon 2 of the $D Q A, D Q B, D R A$, and $D R B$ nucleotide sequences encoded 82, 76,81, and 79 amino acid sequences, respectively. The underlined residues in Fig.1 indicated an assumed ABS, based on the HLA equivalents (Brown et al., 1988; Brown et al., 1993), and may contact the antigen peptides (Fig 1.A-

Peer] reviewing PDF | (2019:09:41277:2:0:NEW 6 Aug 2020) 
160

161

162

163

164

165

166

167

168

169

170

171

172

173

174

175

176

177

178

179

180

181

182

183

184

185

186

D). There were $38(45.12 \%), 51(67.10 \%), 16(19.75 \%)$, and 49 sites $(62.02 \%)$ that were variable in the predicted amino acid sites of the $D Q A, D Q B, D R A$ and $D R B$ of GZP populations, respectively. For the ABS, 17 of 21 sites $(80.95 \%), 12$ of 18 sites $(66.67 \%), 5$ of 20 sites $(25.00 \%)$, and 13 of 14 sites $(92.85 \%)$ were diverse at the $D Q A, D Q A, D Q B, D R A$ and $D R B$ loci. The amino acid compositions of $D Q A, D Q B, D R A$, and $D R B$ at ABS were calculated using MEGA 7 software (Fig. 2). There were more polar R-amino acids at the DQA locus (46.30 \%), and included Gly, Cys, Ser, Tyr, Thr, Asn, and Gln (Fig. 2). The non-polar R-amino acids at the DRA locus had the highest percentage (58.86\%), and included Ala, Leu, Val, Trp, Ile, Phe, Pro, and Met (Fig. 2). The largest proportion of charged R-amino acids (30.70\%) was located at $D Q B$, and consisted of Arg, Lys, His, Glu, and Asp (Fig. 2).

\section{Global selection analyses}

The Wu-Kabat variability index was not used to select all of the variable amino acids (Wu et al., 1970). A total of fifteen amino acids at the $D Q A$ locus were strongly selected at residues $10,17,18,21,23,30,46,51,52$, $58,60,61,62,65$ and 72, with the highest variability occurring at residue 60 (Fig. 3). Many polymorphic sites were observed at the $D Q B$ locus, with eight high mutation loci at residues at $16,27,38,46,47,57,61$, and 65 (Fig. 3). 12 residues were found to be polymorphic at the DRA locus, including residues at 12, 14, 15, 19, 29, 39, 47, 49, 63, 64, 67 and 69 (Fig.3). Amino acid residues at six different positions in the DRB locus had high values (more than 30 ) on the $\mathrm{Wu}-\mathrm{Kabat}$ variability index, and the strongly selected amino acid regions were found at residues 1, 2, 4, 5, 6, 7, 8, 12, 19, 28, 36, 47, 48, 50, 56, 58, 61, 62, 65 and 69 (Fig. 3). A comparison of the $d_{\mathrm{N}} / d_{\mathrm{S}}$ ratio averaged across the whole coding region suggested that positive selection occurred at loci $D Q B$ $\left(d_{\mathrm{N}} / d_{\mathrm{S}}=1.127, \mathrm{p}=0.322\right)$ and $D R B\left(d_{\mathrm{N}} / d_{\mathrm{S}}=1.228, \mathrm{p}=0.202\right)$, and purifying selection appeared at $D Q A\left(d_{\mathrm{N}} / d_{\mathrm{S}}=\right.$ 0.779, $\mathrm{p}=0.143)$ and $D R A\left(d_{\mathrm{N}} / d_{\mathrm{S}}=0.560, \mathrm{p}=0.069\right)$ (Table 3). All codon sites were not statistically significant according to the Z-tests ( $\mathrm{p}>0.05$, Table 3). The estimates of $d_{\mathrm{N}} / d_{\mathrm{S}}$ suggested that $D Q A$ and $D R A$ were not affected by the positive selection at the genetic level.

\section{Site-specific selection analyses}

It is unlikely for selection to act uniformly across MHC genes over evolutionary time. Selection was more likely to occur at specific codons based on their functional role. The rate of nonsynonymous substitutions for the ABS $\left(d_{\mathrm{N}}=0.594 \pm 0.132\right)$ exceeded the number of synonymous substitutions four times $\left(d_{\mathrm{S}}=0.128 \pm 0.080\right)$ at the 
187 188

$D R B$ (Table 3). Our results are in agreement with those observed in the Argentine Creole horse, which exhibited rates of nonsynonymous substitutions more than four times the number of synonymous substitutions at exon 2 of ELA-DRB (Díaz et al., 2001). The ABS rates of synonymous substitutions and nonsynonymous substitutions for $D Q A$ and $D Q B$ were similar $\left(d_{\mathrm{N}}=0.330 \pm 0.088, d_{\mathrm{S}}=0.287 \pm 0.110 ; d_{\mathrm{N}}=0.206 \pm 0.079, d_{\mathrm{S}}=0.133 \pm 0.076\right.$, respectively) (Table 3). The ABS sites at the DRA exhibited less nonsynonymous substitutions $\left(d_{\mathrm{N}}=0.017 \pm 0.008\right)$ than synonymous substitutions $\left(d_{\mathrm{S}}=0.028 \pm 0.022\right)$ with a $d_{\mathrm{N}} / d_{\mathrm{S}}$ ratio of 0.607 (Table 3). Ztests performed separately on ABS were significant for $D R B(\mathrm{p}=0.001)$ providing evidence for positive selection at these sites. We could not reject the null hypothesis of neutral evolution at the non-ABS site (Table 3). The Ztests by site type at the $D Q A, D Q B$, and $D R A$ sites could not reject the null hypothesis of neutrality ( $\mathrm{p}>0.05$ ). In contrast, the non-ABS sites showed more synonymous substitutions than nonsynonymous substitutions with $d_{\mathrm{N}} / d_{\mathrm{S}}$ ratios of $0.581,0.895,0.520$, and 0.678 at $D Q A, D Q B, D R A$ and $D R B$, respectively (Table 3).

The results from the selection analyses in PAML revealed different levels of selection for the four loci (Table 4). The variable evolutionary rates across the codon sites (M3) fit our data better than the M0 model and models M2a and M8 had higher log-likelihoods than positive selection (M1a and M7). The M2a and M8 models implied that approximately $2 \%$ of sites may be under positive selection at the $D Q A$ site $(\omega=8.583, \omega=8.425)$ (Table 4). The posterior means of $\omega$ were estimated across the $D Q A$ codons under positive selection models and predicted fourteen sites (positions $10,17,18,30,46,51,52,60,61,65,68,69,70,72$ ) that may be under selection $(\omega>1)$, nine $(10,30,46,51,52,61,65,68$, and 72) of which were also putative ABS, based on the HLA equivalents (Fig. 4). However, the discrete model (M3: 3 discrete evolutionary rate classes) had the highest loglikelihood and estimated that only $6.6 \%$ of codon sites had $\omega$ values greater than one $(\omega=10.031)$ with the remaining $93.4 \%$ of sites being assigned $\omega$ values close to 0 (Table 4).

However, the posterior means of $\omega$ across $D Q B$ codon sites estimated by M2a $(\omega=6.240)$ and M8 $(\omega=6.373)$ predicted that only five codons were under significant positive selection (positions 16, 27, 47, 57, 61). These five codons were also known as putative ABS based on the HLA equivalents (Fig. 4). The M3 model at the $D Q B$ estimated that approximately $8 \%$ of codon sites had $\omega$ values greater than one $(7.3 \%$ with $\omega=1.283 ; 0.6 \%$ with $\omega=6.935)$ with the remaining $92 \%$ of sites being assigned $\omega$ values close to $0(\omega=0.054)$ (Table 4).

The M3 model estimated that only $6.6 \%$ of codon sites had $\omega$ values greater than one $(\omega=10.031)$ with 
214

215

216

217

218

219

220

221

222

223

224

225

226

227

228

229

230

231

232

233

234

235

236

237

238

239

240

the remaining $93.4 \%$ of sites being assigned $\omega$ values close to 0 for the $D R A$ (Table 4). Moreover, the posterior means of $\omega$ across the $D R A$ codon sites estimated by M2a $(\omega=10.286)$ and M8 $(\omega=10.323)$ predicted that nine codons (positions 12, 14, 15, 16, 18, 19, 49, 64, 68) were under significant positive selection. However, only two sites (19 and 49) were known as putative ABS based on the HLA equivalents (Fig. 4).

The M3 model estimated that $14.6 \%$ of codon sites had $\omega$ values greater than one $(\omega 1=1.351, \omega 2=6.823)$ at the $D R B$ (Table 4), which was higher than the other MHC class II codons ( $D Q A, D Q B$ and $D R A)$. The posterior means of $\omega$ across the $D R B$ codon sites were estimated by the M2a $(\omega=5.972)$ and M8 $(\omega=5.961)$ models and predicted that twelve codons (positions $1,2,23,28,47,48,58,61,62,65,69$, and 77) were under significant positive selection, seven $(2,28,48,58,61,69$, and 77$)$ of which were also putative ABS based on the HLA equivalents (Fig. 4).

\section{Evolutionary analysis}

We could not determine the genealogy of $D Q A, D Q B, D R A$ and $D R B$ due to the presence of loops in the network (Fig 5.A-D). Some alleles were more likely to be ancestral based on their internal position in the network and a greater frequency of mutational connections. These alleles seemed more likely to be ancestral at the $D Q A$ locus, including $D Q A 1, D Q A 3$, Eqca17, and Eqca18. Allele DQA1 appears to be ancestral for most alleles, namely DQA12, DQA13, DQA14, DQA15, DQA9, Eqca10, Eqbu6, Eqca20, Eqas1, Eqas2, Eqbu5, Eqca19, Eqbu4, and Eqbu12. Three haplotypes of Przewalski's horse (Eqpr 3, Eqpr4 and Eqpr2) were separated from DQA3 by two mutational steps and were most closely related to GZP haplotypes. Meanwhile, the $D Q A 1$ allele was shared among four species (Eqca15, Eqgr1, Eqbu2 and Eqze1), DQA2 was shared with Eqca14, and DQA3 was shared between two species (Eqcal6 and Eqbu20). At the $D Q B$ locus, allele $D Q B 1$ appears to be ancestral for most alleles, including $D Q B 31, D Q B 23, D Q B 32, D Q B 10, D Q B 30, D Q B 33, D Q B 29, D Q B 3, D Q B 24, D Q B 34$, $D Q B 40$, Eqas 7 and Eqas4. We found that haplotypes DQB5 and DQB13 were shared between Eqcal and Eqca7, respectively. Allele $D R A 5$ was shared between Eqbu 7 and Eqca5, and $D R A 1$ was shared with $D R A 3$ for the $D R A$ locus. Interestingly, allele $D R A 1$ seemed more likely to be ancestral, containing twenty alleles, including $D R A 21$, DRA15, DRA13, DRA8, DRA18, DRA7, DRA14, DRA6, DRA20, DRA19, DRA17, DRA16, DRA2, DRA11, DRA10, DRA12, Eqca2, Eqca6, Eqca7, and Eqca8. Haplotypes Eqhe and DRA9 were separated from DRA1 by as two mutations step as are most closely related GZP haplotypes. Allele DRA5 seemed more likely to be 
241

242

243

244

245

246

247

248

249

250

251

252

253

254

255

256

257

258

259

260

261

262

263

264

265

266

267

ancestral, Eqbu, Eqze, Eqgr, Egas were separated from DRA5 by one or two mutational step and are most closely related to the GZP haplotypes. Most $D R B$ alleles were dispersed throughout the whole network, and there was a closer genetic relationship between GZP and other horse species. Wild ass haplotypes, Eqas3, Eqas4 and Eqas6, were separated from $D R B 28$ by one mutational step, as are most closely-related GZP haplotypes. Furthermore, the haplotypes DRB2 (Eqpr1) and DRB3 (Eqpr2) were shared by GZP and Przewalski's horse. The haplotypes DRB1 (Eqca5), DRB2 (Eqca12), DRB4 (Eqca7), DRB5 (Eqca1), DRB15 (Eqca2) and DRB23 (Eqca8) were shared between GZP and the European horse.

\section{DISCUSSION}

Our study revealed the diversity of the four ELA class II gene regions, $D Q A, D Q B, D R A$ and $D R B$, and the contribution of many novel alleles identified in GZP. Our data determined within-species variation using the numbers of alleles. $21 D Q A$ alleles, $45 D Q B$ alleles, $22 D R A$ alleles, and $31 D R B$ alleles were unequivocally identified from the GZP.

The DRA locus was relatively well-conserved in four GZP loci compared with the other three loci. The alignments of the $D Q A, D Q B$, and $D R B$ genes revealed considerable sequence diversity. However, $D R A$ had a lower nucleotide diversity. Our results are consistent with the level of nucleotide diversity at the genus level for Equus ELA genes as reported by Kamath et al (2011). $D Q B$ had the highest level of polymorphisms with a ratio of polymorphic sites of $46.08 \%$, this was followed by $D R B$ and $D Q A$. DRA had the lowest level of polymorphisms (15.04 \%), which was consistent with the results of the DRA locus in dogs (Wagner et al., 1999), cats (Yuhki et al., 1995), goats (Takada et al., 1998), and pigs (Chardon et al., 1999). The genetic diversity of ELA is reportedly important for immune functions involving the resistance and susceptibility to pathogens (Trowsdale et al., 2004) with a probable mechanism of gene selection in the evolution process of the pony (Penn et al., 1999).

We detected the balancing selection events by determining the rate of non-synonymous/synonymous substitutions $\left(d_{\mathrm{N}} / d_{\mathrm{S}}\right.$ ratio) of nucleotides. Our results revealed a high genetic variability at the $D Q A, D Q B, D R A$, and $D R B$ loci. The $d_{\mathrm{N}} / d_{\mathrm{S}}$ ratio $\left(d_{\mathrm{N}} / d_{\mathrm{S}}=0.560\right)$ at the $D R A$ locus was the lowest, which was similar to the low levels of polymorphisms detected by sequence alignment. It has been established that the number of synonymous substitutions is greater than non-synonymous substitutions due to strong functional and structural constraints on 
268

269

270

271

272

273

274

275

276

277

278

279

280

281

282

283

284

285

286

287

288

289

290

291

292

293

294

the protein (Kamath et al., 2011). The number of polymorphisms at the $D R A$ locus may be attributed to the selective pressure for DRA haplotypes that present pathogenic antigens for the host species more efficiently (Albright-Fraser et al., 1996).

We found nine $D Q A$ codons, five $D Q B$ codons, nine $D R A$ codons, and seven $D R B$ codons under significant positive selection. The majority of these codons were predicted to be the ABS of ELA. The amino acids under site-specific selection were located on the protein surface based on SWISS-MODEL prediction results (Fig. 4) and were found on the inner surface of the MHC cleft with bound peptides in the antigen presentation (Madden et al., 1995). Several reports indicated that the diversity and nonsynonymous mutations at the ABS could improve the host's ability to recognize pathogens (Hughes et al., 1988; Hughes et al., 1989). These data suggest that the different rates of non-synonymous and synonymous substitutions in $D Q A, D Q B, D R A$ and $D R B$ were closely related to the ABS changes in the GZP. In particular, the $d_{\mathrm{N}} / d_{\mathrm{S}}$ ratio in the ABS was greater than that in the non-ABS region at the $D Q A, D Q B$ and $D R B$ loci, which is common in the Argentine Creole horse (Díaz et al., 2001). The $d_{\mathrm{N}} / d_{\mathrm{S}}$ ratio of ABS was higher than the other regions, which may be due to balancing selection (Albright-Fraser et al., 1996), and the positive selection results in MHC polymorphisms (Yang et al., 2000).

The haplotype median network of $D Q A, D Q B, D R A$ and $D R B$ between GZP and other horses (Eqca, E. callabus; Eqpr, E. przewalski; Eqki, E. kiang; Eqgr, E. grevyi; Eqas, E. asinus; Eqbu, E. burchelli; Eqze, E. zebra; Eqhe, E. hemionus) were analyzed. Among these, several wild ass haplotypes were separated from $D Q A 1$, $D Q B 1$, and $D R B 28$ by one or two mutational steps and are more closely related to GZP haplotypes. The divergence time between the horse and ass has been estimated to be 0.88-2.3 Ma (Krüger et al., 2005). One $E$. hemionus haplotype (Eqhe2) was separated from $D R A$ by two mutational steps and is most closely related to GZP haplotypes. It suggested that $D Q A 1, D Q A 3, D Q B 1, D R A 1, D R A 5$, and $D R B 28$ may be the oldest alleles. The haplotypes DRB2 and DRB3 were shared between GZP and the Przewalski's horse at the DRB locus. Przewalski's horse haplotypes Eqpr3, Eqpr4 and Eqpr2 were separated from DQA3 by two mutational steps. Przewalski's horse was discovered on the Asian steppes in the 1870s and it is the only surviving species of wild horse in the world (Wakefield et al., 2002). It is thought that the Przewalski's horse and the domesticated horse populations separated about 45,000 years ago and maintained a certain degree of gene-flow (Der Sarkissian et al., 2015). Some haplotypes were shared between the GZP and European horses, including $D Q A 1, D Q A 3, D Q B 5$, 
295

296

297

298

299

300

301

302

303

304

305

306

307

308

309

310

311

312

313

314

315

316

317

318

319

320

321

$D Q B 13, D R B 1, D R B 2, D R B 15, D R B 23, D R B 4$, and $D R B 5$. The allele $D Q A 1$ appears to be the ancestor for the three alleles, Eqca10, Eqca20, and Eqca19. Allele DRA1 seemed more likely to be ancestral for four alleles, including Eqca2, Eqca6, Eqca7, and Eqca8. The genes of the domesticated Asian horse may have dispersed into European populations because of the gene flow (Bjørnstade al., 2003). Interestingly, the haplotypes DQA1, $D Q A 3$, and DRA5 were shared between the GZP and E.burchelli, E.grevyi and zebra. The divergence time between horses and zebras is estimated to be 0.86-2.3 Ma based on microsatellite trees (Krüger et al. 2005). The common ancestor of all extant forms may have existed about 3.9 Ma, and speciation leading to the zebra, ass, and horse may have occurred within the following $0.5 \mathrm{Ma}$ (George et al., 1986). These data and our results indicated that the GZP is an ancient variety of equid. Additional studies on the GZP may advance our knowledge of unique haplotypes and their roles in the adaptation to local environmental pressures such as the unique pathogenic microorganisms in the mountainous and humid districts in Guizhou province, China.

\section{CONCLUSION}

Nucleotide diversity was detected from exon 2 of $E L A-D Q A, D Q B, D R A$, and $D R B$ genes in the GZP using direct sequencing technology. Of those four loci, the $D R A$ locus was relatively well-conserved and possessed the lowest diversity. Many codons in the ABS underwent positive selection, including nine $D Q A$ codons, five $D Q B$ codons, nine $D R A$ codons, and seven $D R B$ codons. The amino acids coded by selected codons were found on the inner surface of the cleft of the ELA complex and were bound to an antigen peptide. The selected sites may be related to the GZP's ability to defend against foreign pathogens from the surrounding habitat. Many ancient alleles were detected at the $D Q A, D Q B, D R A$ and $D Q B$ gene regions of GZP. Two older haplotypes of $D R B$ (DRB2 and $D R B 3$ ) were shared by the GZP and Przewalski's horse. Two older haplotypes of DRA (DRA1 and DRA5) were separated from Eqbu, Eqze, Eqgr, and Egas by one or two mutations steps, and four older haplotypes of GZP (DQA1, DQA3, DQB1, and DRB28) were closer to the wild ass and Przewalski's horse by only one or two mutational steps. The indigenous breed, GZP, may have retained ancient haplotyes in ELA genes. There may be a large number of unique haplotypes dispersed in GZP resulting from the long process of ELA molecule evolution. The unique genetic characteristics of GZP have been unclear, undervalued, and confused with other ponies. The genetic uniqueness revealed in our study is helpful to understand its genetic conservation of this ancient variety of pony.

Peer) reviewing PDF | (2019:09:41277:2:0:NEW 6 Aug 2020) 
323

324

325

326

327

328

329

330

331

332

333

334

335

336

337

338

339

340

References

Albright-Fraser DG, Reid R, Gerber V, Bailey E. 1996. Polymorphism of DRA among equids. Immunogenetics 43(5):315-7.

Anisimova M, Bielawski JP, Yang Z. 2001. Accuracy and power of the likelihood ratio test in detecting adaptive molecular evolution. Mol Biol Evol. (8):1585-92.

Anisimova M, Nielsen R, Yang Z. 2003. Effect of recombination on the accuracy of the likelihood method for detecting positive selection at amino acid sites. Genetics (3):1229-36.

Ansari HA, Hediger R, Fries R, Stranzinger G.1988. Chromosomal localization of the Major Histocompatibility Complex of the horse (ELA) by insitu hybridization. Immunogenetics 28(5):362-364.

Bandelt HJ, Forster P, Röhl A. 1999. Median-joining networks for inferring intraspecific phylogenies.MolBiolEvol 16(1):37-48 DOI: 10.1093/oxfordjournals.molbev.a026036.

Bernatchez L, Landry C. 2003. MHC studies in nonmodel vertebrates: what have we learned about natural selection in 15 years? J Evol Biol 16(3):363-77.

Biasini M, Bienert S, Waterhouse A, Arnold K, Studer G, Schmidt T, Kiefer F, Gallo Cassarino T, Bertoni M, Bordoli L, Schwede T. 2014. SWISS-MODEL: modelling protein tertiary and quaternary structure using evolutionary information. Nucleic Acids Res 42:W252-8.

Bielawski JP, Yang Z. 2003. Maximum likelihood methods for detecting adaptive evolution after gene duplication. J Struct Funct Genomics 3(1-4):201-12.

Bjørnstad G, Nilsen NØ, Røed KH. 2003. Genetic relationship between Mongolian and Norwegian horses? Anim Genet 34(1):55-8.

Bolnick DI, Stutz WE. 2017. Frequency dependence limits divergent evolution by favouring rare immigrants over residents. Nature. 2017;546(7657):285-288.

Bontrop RE, Otting N, de Groot NG, Doxiadis GG. 1999. Major histocompatibility complex class II polymorphisms in primates. Immunol Rev 167:339-50.

Brown JJ, Thomson W, Clegg P, Eyre S, Kennedy LJ, Matthews J, Carter S, Ollier WE. 2004. Polymorphisms of the equine major histocompatibility complex class II DRA locus. Tissue Antigens 
349

350

351

352

353

354

355

356

357

358

359

360

361

362

363

364

365

366

367

368

369

370

371

372

373

374

375

64(2):173-9 DOI: 10.1111/j.1399-0039.2004.00269.x.

Brown JH, Jardetzky T, Saper MA, Samraoui B, Bjorkman PJ, Wiley DC. 1988. A hypothetical model of the foreign antigen binding site of class II histocompatibility molecules. Nature 333(6175):786 DOI: $10.1038 / 332845 \mathrm{a} 0$.

Brown JH, Jardetzky TS, Gorga JC, Stern LJ, Urban RG, Strominger JL, Wiley DC.1993. Threedimensional structure of the human class II histocompatibility antigen HLA-DR1. Nature. 364(6432):33-9. DOI: $10.1038 / 364033 \mathrm{a} 0$

Buhler S, Nunes JM, Sanchez-Mazas A. 2016. HLA class I molecular variation and peptide-binding properties suggest a model of joint divergent asymmetric selection. Immunogenetics 68(6-7):401-416.

Chardon P, Renard C, Vaiman M. 1999. The major histocompatibility complex in swine. Immunol Rev $167: 179-92$.

Cutrera AP, Lacey EA .2007. Trans-species polymorphism and evidence of selection on class II MHC loci in tuco-tucos (Rodentia: Ctenomyidae). Immunogenetics 59(12):937-48 DOI: 10.1007/s00251-007-0261-3.

Der Sarkissian C, Ermini L, Schubert M, Yang MA, Librado P, Fumagalli M, Jónsson H, Bar-Gal GK, Albrechtsen A, Vieira FG, Petersen B, Ginolhac A, Seguin-Orlando A, Magnussen K, Fages A, Gamba C, Lorente-Galdos B, Polani S, Steiner C, Neuditschko M, Jagannathan V, Feh C, Greenblatt CL, Ludwig A, Abramson NI, Zimmermann W, Schafberg R, Tikhonov A, SicheritzPonten T, Willerslev E, Marques-Bonet T, Ryder OA, McCue M, Rieder S, Leeb T, Slatkin M, Orlando L. 2015. Evolutionary Genomics and Conservation of the Endangered Przewalski's Horse. Curr Biol 25(19):2577-83 DOI: 10.1016/j.cub.2015.08.032.

Díaz S, Giovambattista G, Dulout FN, Peral-García P. 2001. Genetic variation of the second exon of ELADRB genes in Argentine Creole horses. Anim Genet 32(5):257-63.

Edwards SV, Hedrick PW.1988. Evolution and ecology of MHC molecules: from genomics to sexual selection. Trends Ecol Evol 13(8):305-11.

Eizaguirre C, Lenz TL, Kalbe M, Milinski M.2012. Rapid and adaptive evolution of MHC genes under parasite selection in experimental vertebrate populations. Nat Commun 3:621.

Figueroa F, Günther E, Klein J. 1988. MHC polymorphism pre-dating speciation. Nature 335(6187):265-7

Peer) reviewing PDF | (2019:09:41277:2:0:NEW 6 Aug 2020) 
DOI: $10.1038 / 335265 \mathrm{a} 0$.

Fraser DG, Bailey E.1996. Demonstration of three DRB loci in a domestic horse family. Immuno genetics 44(6):441-5 DOI: 10.1007/bf02602805.

Fraser DG, Bailey E.1998. Polymorphism and multiple loci for the horse DQA gene. Immunogenetics 1998, 47(6):487-490.

George M Jr, Ryder OA. 1986. Mitochondrial DNA evolution in the genus Equus. Mol Biol Evol 3(6):535-46 DOI: 10.1093/oxfordjournals.molbev.a040414.

Hill AV. 2001. The genomics and genetics of human infectious disease susceptibility. Annu Rev Genomics Hum Genet 2:373-400 DOI: 10.1146/annurev.genom.2.1.373.

Hughes AL, Nei M. 1988. Pattern of nucleotide substitution at major histocompatibility complex class I loci reveals overdominant selection. Nature 335(6186):167-70 DOI: 10.1038/335167a0.

Hughes AL, Nei M.1989.Nucleotide substitution at major histocompatibility complex class II loci: evidence for overdominant selection. Proc Natl AcadSci U S A 86(3):958-62 DOI: 10.1073/pnas.86.3.958.

Hughes AL, Hughes MK. 1995. Natural selection on the peptide-binding regions of major histocompatibility complex molecules. Immuno genetics 42(4):233-43 DOI: 10.1007/bf00176440.

Janova E, Matiasovic J, Vahala J, Vodicka R, Van Dyk E, Horin P. 2009. Polymorphism and selection in the major histocompatibility complex DRA and DQA genes in the family Equidae. Immunogenetics 61(7):513-27 DOI: 10.1007/s00251-009-0380-0.DOI: 10.1007/s00251-009-0380-0.

Kamath PL, Getz WM. 2011. Adaptive molecular evolution of the Major Histocompatibility Complex genes, DRA and DQA, in the genus Equus. BMC Evol Biol 11:128. DOI: 10.1186/1471-2148-11-128.

Klein J, Satta Y, Takahata N, O'hUigin C.1993.Trans-specific Mhc polymorphism and the origin of species in primates. J Med Primatol 22(1):57-64.

Kloch A, Babik W, Bajer A, Siński E, Radwan J. 2010. Effects of an MHC-DRB genotype and allele number on the load of gut parasites in the bank vole Myodesglareolus. Mol Ecol 19 Suppl 1:255-65.

Kumar S, Stecher G, Tamura K. 2016. MEGA7: Molecular Evolutionary Genetics Analysis Version 7.0 for Bigger Datasets. Mol Biol Evol. 33(7):1870-4. DOI: 10.1093/molbev/msw054.

Krüger K, Gaillard C, Stranzinger G, Rieder S. 2005. Phylogenetic analysis and species allocation of 
403

404

405

406

407

408

409

410

411

412

413

414

415

416

417

418

419

420

421

422

423

424

425

426

427

428

429

individual equids using microsatellite data. 122 Suppl 1:78-86.

Kubinak JL, Ruff JS, Hyzer CW, Slev PR, Potts WK. 2012. Experimental Viral Evolution to Specific Host MHC Genotypes Reveals Fitness and Virulence Trade-Offs in Alternative MHC Types. Proc Natl Acad Sci U S A 109(9):3422-7.

Landry C, Bernatchez L. 2001.Comparative analysis of population structure across environments and geographical scales at major histocompatibility complex and microsatellite loci in Atlantic salmon (Salmo salar). Mol Ecol 10(10):2525-39.

Lau Q, Chow N, Gray R, Gongora J, Higgins DP. 2015.Diversity of MHC DQB and DRB Genes in the Endangered Australian Sea Lion (Neophoca cinerea). J Hered 106(4):395-402.

Lenz TL, Wells K, Pfeiffer M, Sommer S. 2009. Diverse MHC IIB Allele Repertoire Increases Parasite Resistance and Body Condition in the Long-tailed Giant Rat (Leopoldamys Sabanus). BMC Evol Biol 9:269.

Lenz TL, Eizaguirre C, Kalbe M, Milinski M. 2013. Evaluating patterns of convergent evolution and transspecies polymorphism at MHC immunogenes in two sympatric stickleback species. Evolution 67(8):240012.

Lenz TL. 2011. Computational prediction of MHC II-antigen binding supports divergent allele advantage and explains trans-species polymorphism. Evolution. $2011 ; 65(8): 2380-90$.

Levitan DR, Ferrell DL. 2006. Selection on gamete recognition proteins depends on sex, density, and genotype frequency. Science 312, 267-269.

Lewin HA, Russell GC, Glass EJ. 1999. Comparative organization and function of the major histocompatibility complex of domesticated cattle. Immunol Rev. 167:145-58.

Li L, Wang BB, Ge YF \& Wan QH. 2014. Major histocompatibility complex class II polymorphisms in forest musk deer (Moschus berezovskii) and their probable association with purulent disease. International Journal of Immunogenetics 41, 401-12.

Lian XD, Zhang XH, Dai ZX, Zheng YT. 2017. Characterization of Classical Major Histocompatibility Complex (MHC) Class II Genes in Northern Pig-Tailed Macaques (Macaca Leonina). Infect Genet Evol.56:26-35. 
430

431

432

433

434

435

436

437

438

439

440

Luís C, Cothran EG, Oom MM, Bailey E. 2005. Major histocompatibility complex locus DRA polymorphism in the endangered Sorraia horse and related breeds. J Anim Breed Genet 122(1):69-72.

Mäkinen A, Chowdhary B, Mahdy E, Andersson L, Gustavsson I. 1989.Localizationof the equine Major Histocompatibility Complex (ELA) tochromosome-20 by insitu hybridization. Hereditas 1989, 110(1):9396.

Madden KS, Felten SY, Felten DL, Bellinger DL.1995. Sympathetic nervous system--immune system interactions in young and old Fischer 344 rats. Ann N Y Acad Sci 771:523-34.

Mashima S. 2003. Comparative sequence analysis of equine and human MHC class II DQB genes. Cytogenet Genome Res 102(1-4):196-200 DOI: 10.1159/000075748.

McGahern AM, Edwards CJ, Bower MA, Heffernan A, Park SD, Brophy PO, Bradley DG, MacHugh DE, Hill EW. 2006. Mitochondrial DNA sequence diversity in extant Irish horse populations and in ancient horses. Anim Genet 37(5):498-502DOI: 10.1111/j.1365-2052.2006.01506.x.

Meyer-Lucht Y, Sommer S. 2005. MHC diversity and the association to nematode parasitism in the yellownecked mouse (Apodemus flavicollis).Mol Ecol 14(7):2233-43 DOI: 10.1111/j.1365-294X.2005.02557.x.

Meyer JR, Kassen R. 2007. The effects of competition and predation on diversification in a model adaptive radiation. Nature 446, 432-435.

Miller D, Tallmadge RL, Binns M, Zhu B, Mohamoud YA, Ahmed A, Brooks SA, Antczak DF. 2017. Polymorphism at expressed DQ and DR loci in five common equine MHC haplotypes. Immunogenetics 69(3):145-15 DOI: 10.1007/s00251-016-0964-4.

Nei M, Gojobori T. 1986. Simple methods for estimating the numbers of synonymous and nonsynonymous nucleotide substitutions. Mol Biol Evol 3(5):418-26 DOI: 10.1093/oxfordjournals.molbev.a040410.

O'Connor SL, Blasky AJ, Pendley CJ, Becker EA, Wiseman RW, Karl JA, Hughes AL, O'Connor DH. 2007. Comprehensive characterization of MHC class II haplotypes in Mauritian cynomolgus macaques. Immunogenetics 59(6):449-62.

Paterson S, Wilson K, Pemberton JM. 1998. Major histocompatibility complex variation associated with juvenile survival and parasite resistance in a large unmanaged ungulate population. Proc Natl AcadSci U S A 95(7):3714-9 DOI: 10.1073/pnas.95.7.3714. 
457

458

459

460

461

462

463

464

465

466

467

468

469

470

471

472

473

474

475

476

477

478

479

480

481

482

483

Piertney SB, Oliver MK. 2006. The evolutionary ecology of the major histocompatibility complex.Heredity (Edinb) 96(1):7-21 DOI: 10.1038/sj.hdy.6800724.

Penn DJ, Potts WK. 1999. The Evolution of Mating Preferences and Major Histocompatibility Complex Genes. Am Nat 153(2):145-164 DOI: 10.1086/303166.

Phillips KP, Cable J, Mohammed RS, Herdegen-Radwan M, Raubic J, Przesmycka KJ, van Oosterhout C, Radwan J. 2018. Immunogenetic novelty confers a selective advantage in host-pathogen coevolution. Proc Natl Acad Sci U S A 115(7):1552-1557.

Pierini F, Lenz TL. 2018. Divergent Allele Advantage at Human MHC Genes: Signatures of Past and Ongoing Selection. Mol Biol Evol 35(9):2145-2158.

Prystupa JM, Hind P, Cothran EG, Plante Y. 2012. Maternal lineages in native Canadian equine populations and their relationship to the Nordic and Mountain and Moorland pony breeds. J Hered 103(3):380-90 DOI: 10.1093/jhered/ess003 DOI: 10.1093/jhered/ess003.

Richman AD, Herrera LG, Nash D. 2001. MHC class II beta sequence diversity in the deer mouse (Peromyscus maniculatus): implications for models of balancing selection. Mol Ecol 10(12):2765-73.

Schad J, Ganzhorn JU, Sommer S. 2005. Parasite burden and constitution of major histocompatibility complex in the Malagasy mouse lemur, Microcebus murinus. Evolution 59(2):439-50.

Schwensow N, Dausmann K, Eberle M, Fietz J, Sommer S.2010. Functional associations of similar MHC alleles and shared parasite species in two sympatric lemurs. Infect Genet Evol 10(5):662-8.

Sommer S. 2005. The importance of immune gene variability (MHC) in evolutionary ecology and conservation. Front Zool 2:16 DOI: 10.1186/1742-9994-2-16.

Takada T, Kikkawa Y, Yonekawa H, Amano T.1998. Analysis of goat MHC class II DRA and DRB genes: identification of the expressed gene and new DRB alleles. Immuno genetics. 48(6):408-12 DOI: $10.1007 / \mathrm{s} 002510050452$.

Takahata N, Nei M. 1990. Allelic genealogy under overdominant and frequency-dependent selection and polymorphism of major histocompatibility complex loci. Genetics 124(4):967-78.

Trachtenberg E, Korber B, Sollars C, Kepler TB, Hraber PT, Hayes E, Funkhouser R, Fugate M, Theiler J, Hsu YS, Kunstman K, Wu S, Phair J, Erlich H, Wolinsky S. 2003. Advantage of rare HLA supertype 
484

485

486

487

488

489

490

491

492

493

494

495

496

497

498

499

500

501

502

503

504

505

506

507

508

509

510

in HIV disease progression. Nat Med 9(7):928-35.

Trowsdale J, Parham P. 2004. Mini-review: defense strategies and immunity-related genes. Eur J Immunol 34(1):7-17 DOI: 10.1002/eji.200324693.

Singh VK, Mangalam AK, Dwivedi S, Naik S. 1998. Primer premier: program for design of degenerate primers from a protein sequence. Biotechniques 24(2):318-9.

Wagner JL, Burnett RC, Storb R. 1999. Organization of the canine major histocompatibility complex: current perspectives. J Hered 90(1):35-8 DOI: 10.1093/jhered/90.1.35.

Waterhouse A, Bertoni M, Bienert S, Studer G, Tauriello G, Gumienny R, Heer FT, de Beer TAP, Rempfer C, Bordoli L, Lepore R, Schwede T.2018. SWISS-MODEL: homology modelling of protein structures and complexes. Nucleic Acids Res 46(W1):W296-W303.

Wakefield S, Knowles J, Zimmermann W, van Dierendonck M. 2002. Chapter 7: Status and Action Plan for the Przewalski's Horse (Equus ferus przewalskii) In: Moehlman PD, editor. Equids: Zebras, Asses, and Horses: Status Survey and Conservation Action Plan. IUCN/SCC Equid Specialist Group, IUCN (The World Conservation Union); Gland Switzerland and Cambridge.

Westerdahl H, Wittzell H, von Schantz T, Bensch S. 2004. MHC Class I Typing in a Songbird With Numerous Loci and High Polymorphism Using Motif-Specific PCR and DGGE. Heredity (Edinb) 92(6):534-42.

Wu TT, Kabat EA. 1970. An analysis of the sequences of the variable regions of Bence Jones proteins and myeloma light chains and their implications for antibody complementarity. J Exp Med 132(2):211-50 DOI: 10.1084/jem.132.2.211.

Yuhki N, O'Brien SJ. 1997. Nature and origin of polymorphism in feline MHC class II DRA and DRB genes. J Immunol 158(6):2822-33.

Yang Z, Bielawski JP. 2000. Statistical methods for detecting molecular adaptation. Trends Ecol Evol 15(12):496-503.

Yang Z. 2007. PAML 4: phylogenetic analysis by maximum likelihood. Mol Biol Evol 24(8):1586-91 DOI: 10.1093/molbev/msm088.

Yang Z, Nielsen R, Goldman N, Pedersen AM. 2000. Codon-substitution models for heterogeneous selection 
511 pressure at amino acid sites. Genetics 155(1):431-49. 


\section{Figure 1}

The amino acid alignment of the $D Q A(\mathrm{~A}), D Q B(\mathrm{~B}), D R A(\mathrm{C})$ and $D R B(\mathrm{D})$ locus.

Underlined below amino acids indicated antigen binding sites (ABS). The missing amino acid was denoted with hyphen. 
A

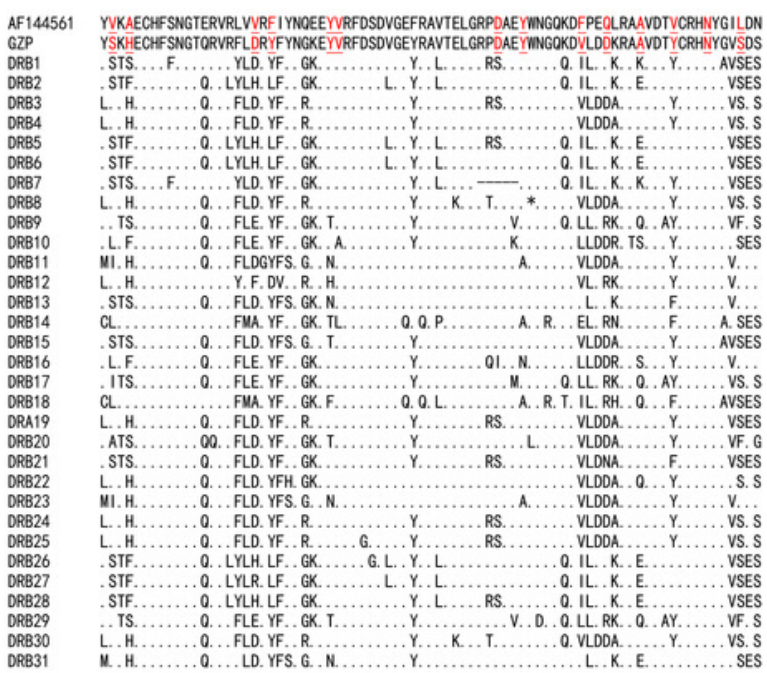

C

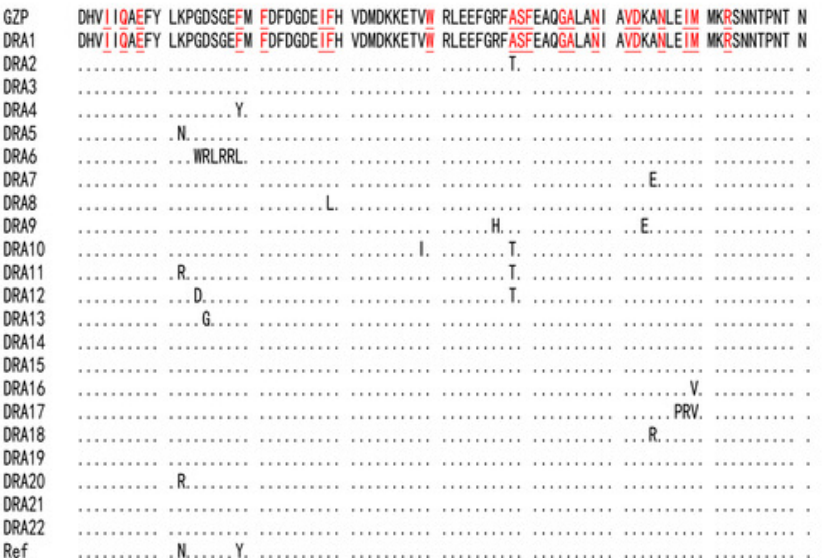

B

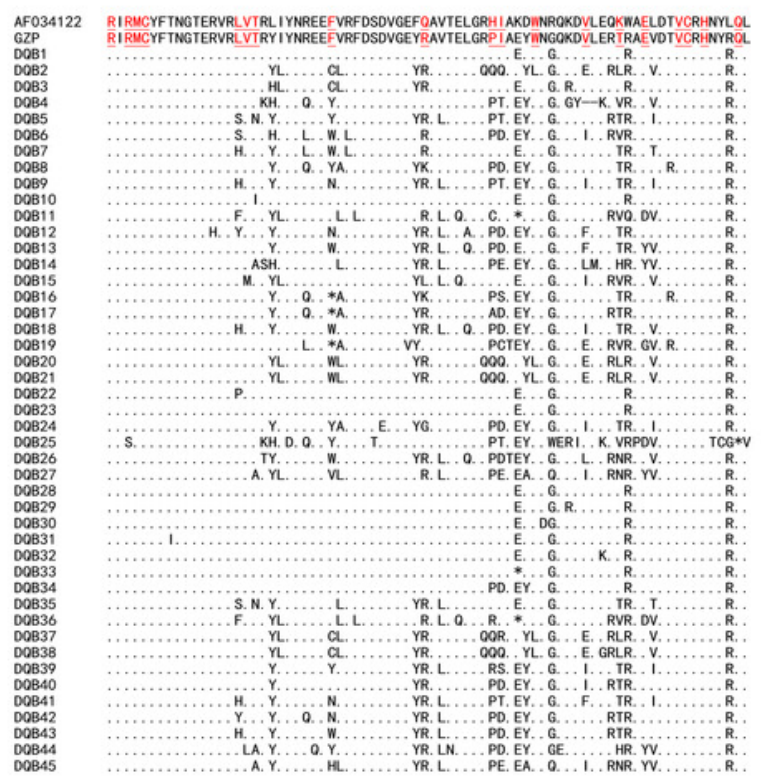

D

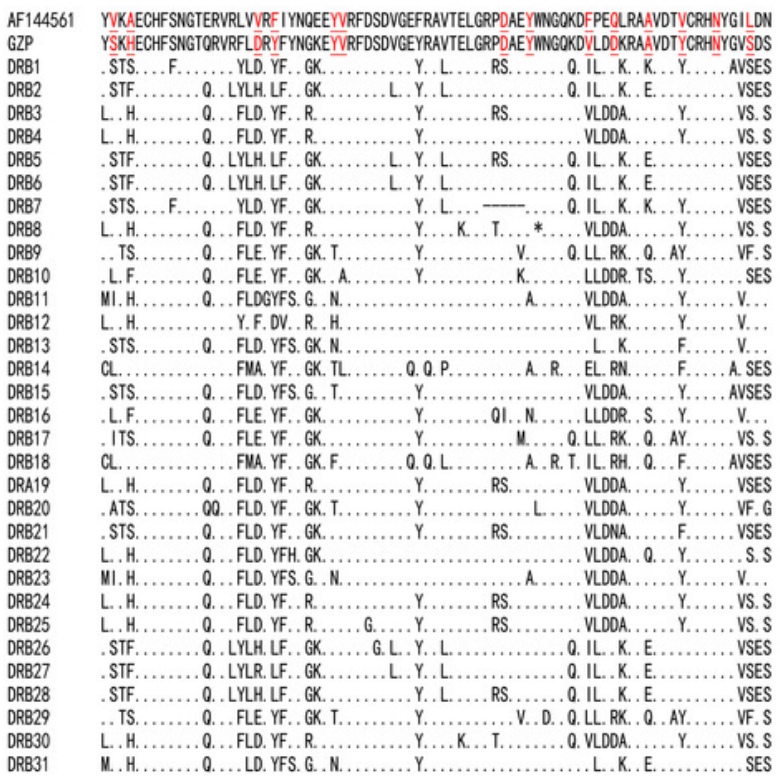




\section{Figure 2}

The distribution of amino acids with non-polar, polar and positively, negatively charged residues.

Non-polar R-amino acids: Ala, Leu, Val, Trp, Ile, Phe, Pro, Met; polar R-amino acids: Gly, Cys, Ser, Tyr, Thr, Asn, GIn; charged R-amino acids: Arg, Lys, His, Glu, Asp.

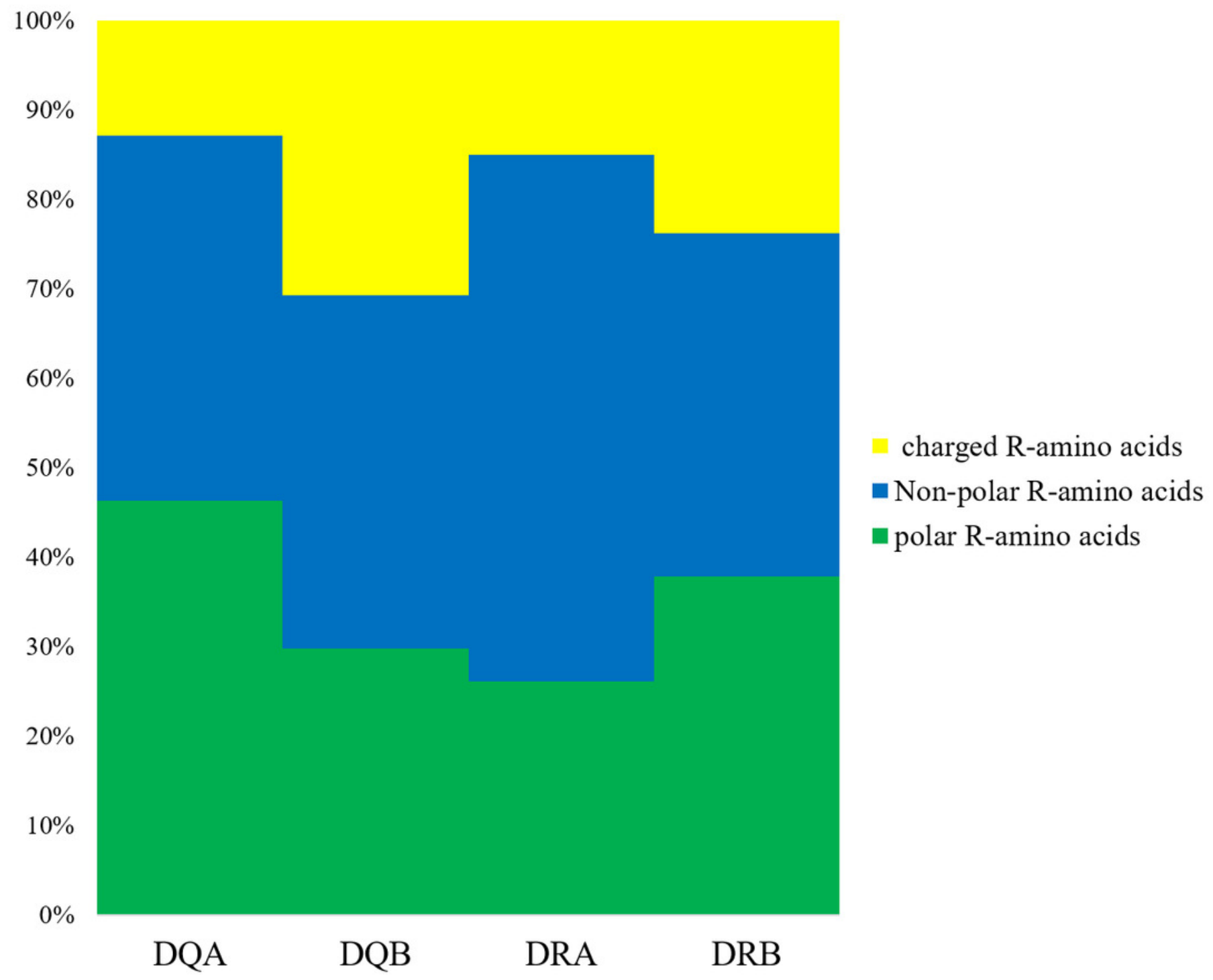


Figure 3

Wu-Kabat variability index of $D Q A(\mathrm{~A}), D Q B(\mathrm{~B}), D R A(\mathrm{C})$ and $D R B(\mathrm{D})$ loci.

The vertical index indicated the Wu-Kabat index at each amino acid position. The horizontal axis showed the consensus amino acids in the DQA, DQB, DRA and DRB peptides. 


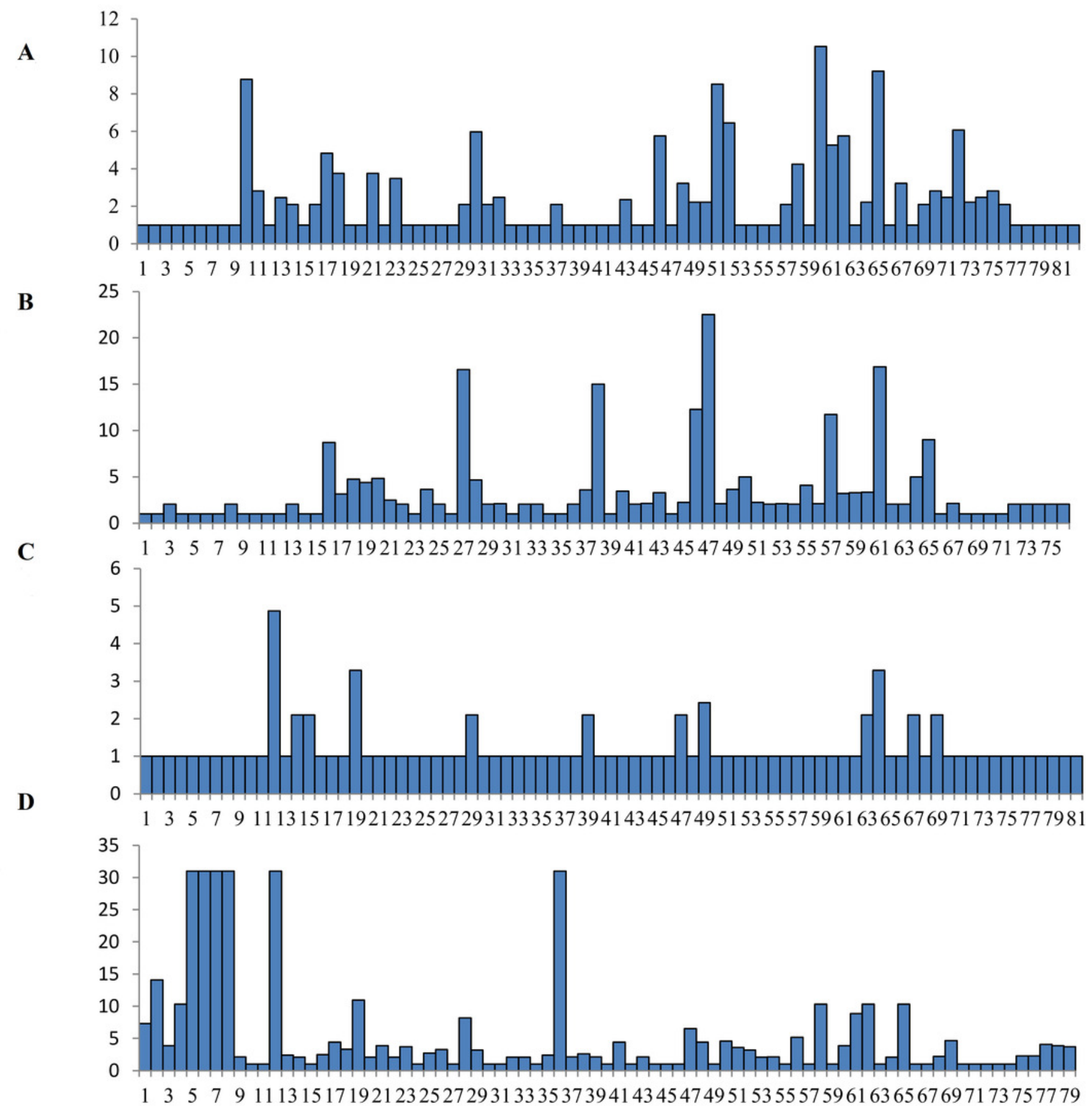




\section{Figure 4}

Fig. 4 The ABS binding residues of $D Q A(\mathrm{~A}), D Q B(\mathrm{~B}), D R A(\mathrm{C})$ and $D R B(\mathrm{D})$ in GZP.

The non-ABS region was circled in white color, the equivalent position of $A B S$ were in red (Non-polar R-amino acids), blue (polar R-amino acids), green (positively charged R-amino acids) and purple (negatively charged R-amino acids), respectively.
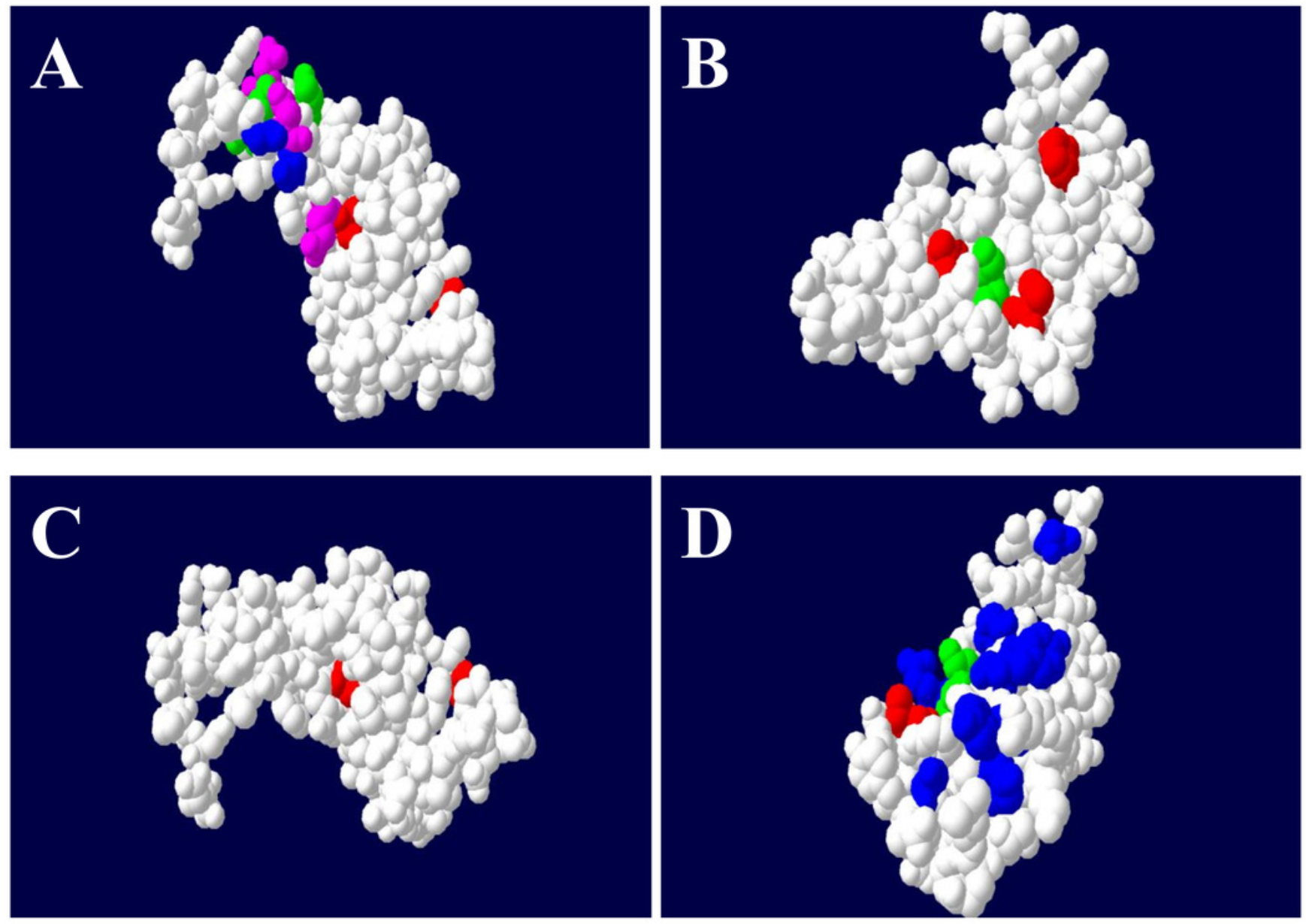
Figure 5

Figure. 5 Median-joining network of $\mathrm{DQA}(\mathrm{A}), \mathrm{DQB}(\mathrm{B}), D R A(C)$ and $D R B(D)$ sequences in the Equidae family.

The circle size was proportional to haplotype frequency.

A
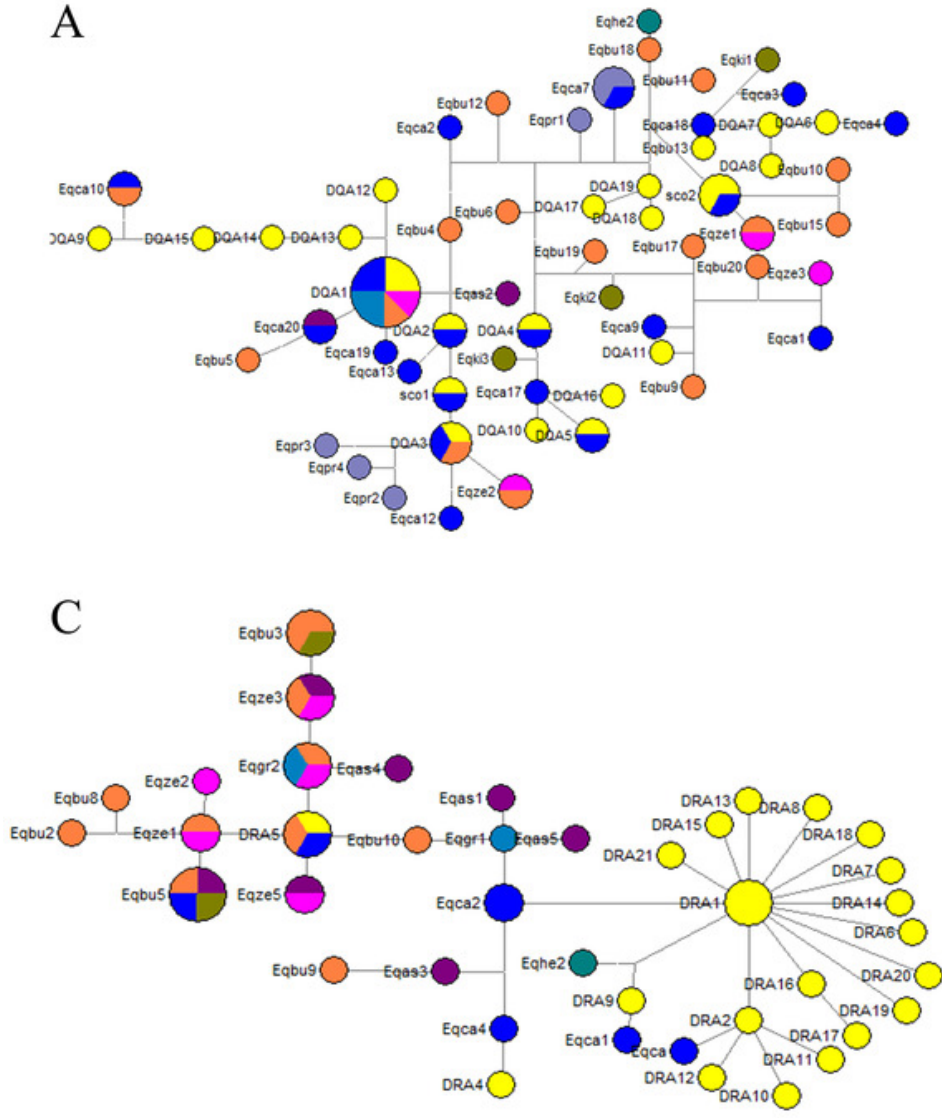

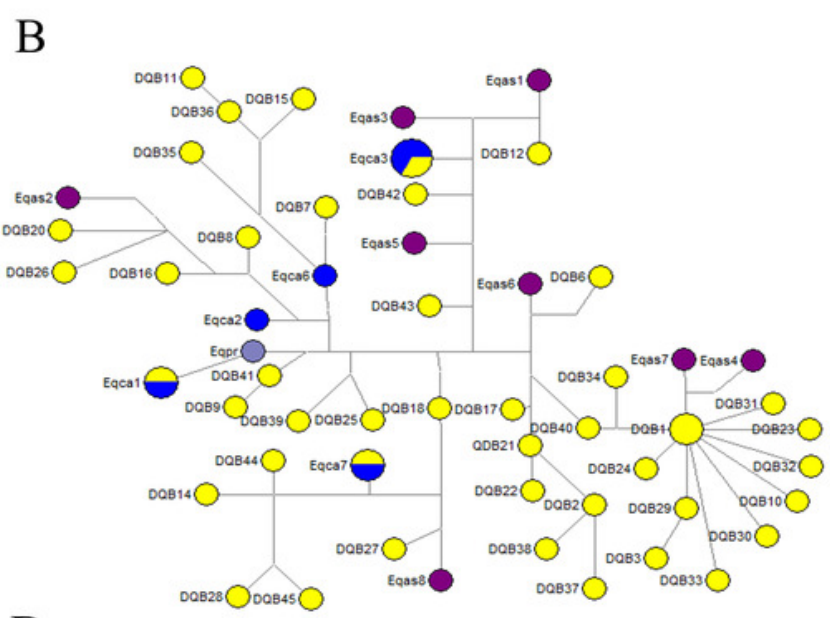

$\mathrm{D}$

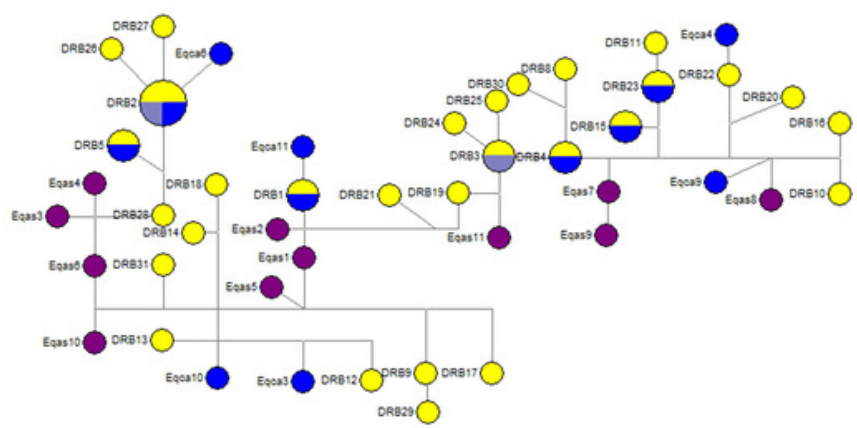


Table $\mathbf{1}$ (on next page)

Table 1 The primers for DRA, DRB, DQA and DQB gene detection. 
1 Table 1 The primers for DRA, DRB, DQA and DQB gene detection.

\begin{tabular}{llll}
\hline Gene name & Primer name & Primer sequence $\left(5^{\prime} \rightarrow 3\right.$ ') & length $(\mathrm{bp})$ \\
\hline DRAexon2 & DRA-F & AGGATCACGTGATCATCCAG & 246 \\
& DRA-R & CATTGGTGTTTGGAGTGTTG & \\
DRBexon2 & DRB-F & CTCTGCAGCACATTTCCTGGAG & 276 \\
& DRB-R & CGCCGCTGCACCAGGAA & 230 \\
DQBexon2 & DQB-F & CTCGGATCCGCATGTGCTACTTCACCAACG & \\
& DQB-R & GAGCTGACGGTAGTTGTGTCTGCACAC & \\
DQAexon2 & DQA-F & CTGATCACTTTGCCTCCTATG \\
& DQA-R & TGGTAGCAGCAGTAGAGTTG & 246 \\
\hline
\end{tabular}

2 


\section{Table 2 (on next page)}

Table 2 General information regarding the horse populations analyzed in this Network study. 
1 Table 2 General information regarding the horse populations analyzed in this Network study.

\begin{tabular}{|c|c|c|c|}
\hline Locus & Breed & Source & GenBank ID \\
\hline$D Q A$ & Guizhou pony & This study & MT304744 - MT304761 \\
\hline$D Q A$ & Equus przewalskii & NCBI & $\begin{array}{l}\text { JX088699, JX088698, JX088697, JX088696, U92509, } \\
\text { U92509 }\end{array}$ \\
\hline$D Q A$ & Equus caballus & NCBI & $\begin{array}{l}\text { AF115329, AF115328, AF115327, AF115326, } \\
\text { AF115325, AF115324, U92508, U92519, } \\
\text { U92518, U92517, U92516, U92515, } \\
\text { U92514, U92513, U92512, U92511, } \\
\text { U92510, U92507, U92506, U92505 }\end{array}$ \\
\hline$D Q A$ & Equus burchellii & NCBI & $\begin{array}{l}\text { EU935835,EU935837, EU935836, EU935834, } \\
\text { EU935833, EU935832, EU935829, EU930130 } \\
\text { HQ637409, HQ637408, HQ637407, } \\
\text { HQ637397, HQ637406, HQ637405, } \\
\text { HQ637404, HQ637403, HQ637402, } \\
\text { HQ637401, HQ637400, HQ637399, } \\
\text { HQ637398, }\end{array}$ \\
\hline$D Q A$ & Equus zebra & NCBI & EU935838, EU935831, EU935830, EU935828 \\
\hline$D Q A$ & Equus grevyi & NCBI & EU930136, EU930131 \\
\hline$D Q A$ & Equus asinus & NCBI & U92522, U92521 \\
\hline$D Q A$ & Equus hemionus & NCBI & U92520, EU930135 \\
\hline$D Q A$ & Equus kiang & NCBI & EU930134, EU930133, EU930132 \\
\hline$D Q B$ & Guizhou pony & This study & MT304705 - MT304743 \\
\hline$D Q B$ & Equus asinus & NCBI & $\begin{array}{l}\text { AF034125, AF034124, AF034123, AF034122, } \\
\text { U31776, U31775, U31774, XM_014839831.1 }\end{array}$ \\
\hline$D Q B$ & Equus przewalskii & NCBI & XM_008508365.1 \\
\hline$D Q B$ & Equus caballus & NCBI & $\begin{array}{l}\text { JQ254069.1, L33910.1, XM_005603501.3, JQ254075.1, } \\
\text { JQ254071.1, NM_001317256.1 }\end{array}$ \\
\hline$D R A$ & Guizhou pony & This study & MT304762 - MT304783 \\
\hline$D R A$ & Equus hemionus & NCBI & L47173, EU930128 \\
\hline$D R A$ & Equus kiang & NCBI & FJ657514, EU930127 \\
\hline$D R A$ & Equus grevyi & NCBI & EU930125, EU930116 \\
\hline$D R A$ & Equus zebra & NCBI & $\begin{array}{l}\text { EU930117, EU930119, EU930123, EU930124, } \\
\text { EU930129 }\end{array}$ \\
\hline$D R A$ & Equus burchellii & NCBI & $\begin{array}{l}\text { EU930118, EU930120, EU930121, EU930122, } \\
\text { EU930126, HQ637392, HQ637393, } \\
\text { HQ637394, HQ637396, HQ637395, } \\
\text { AJ575299 }\end{array}$ \\
\hline$D R A$ & Equus caballus & NCBI & $\begin{array}{l}\text { L47172, L47174, AJ575295, JN035631, } \\
\text { JN035630, JN035629 }\end{array}$ \\
\hline
\end{tabular}




\begin{tabular}{|c|c|c|c|}
\hline$D R A$ & Equus asinus & & $\begin{array}{l}\text { AJ575298, AJ575297, AJ575296, HM165492, } \\
\text { FJ487912, L47171, AF541938 }\end{array}$ \\
\hline$D R B$ & Guizhou pony & This study & MT304784 - MT304811 \\
\hline$D R B$ & Equus przewalskii & NCBI & AF084188.1, XM_008511984.1 \\
\hline$D R B$ & Equus caballus & NCBI & $\begin{array}{l}\text { L76972, L76978, L76976, L76975, L76974, } \\
\text { L76977, L76973, AF170067, L77079, AF144564, } \\
\text { XM_023624024.1, JQ254087.1 } \\
\text { XR_002801945.1, XR_001379170.2, } \\
\text { XM_023624023.1, XM_014734203.2, } \\
\text { XM_014734205.1, NM_001142816.1, } \\
\text { JN035625.1, JQ254096.1, JQ254095.1, } \\
\text { L25644.1, JN035627, JN035623.1, } \\
\text { JN035622.1, JN035621.1, JN035624.1, } \\
\text { JQ254099.1, JN035626.1, JQ254093.1, }\end{array}$ \\
\hline$D R B$ & Equus asinus & $\mathrm{NCBI}$ & $\begin{array}{l}\text { XM_014846373.1, XR_001398881.1, } \\
\text { XM_014846372.1, KJ596517.1, KJ596507.1, } \\
\text { KJ596519.1, KJ596510.1, KJ596510.1, } \\
\text { KJ596516.1, KJ596511.1, KJ596518.1, } \\
\text { KJ596512.1, KJ596514.1, KJ596515.1 }\end{array}$ \\
\hline
\end{tabular}




\section{Table 3 (on next page)}

Table 3 The Indices of selection at the DQA, DQB, DRA and DRB loci.

aa distance: average pair-wise amino acid distance; $d_{\mathrm{N}}$ nonsynonymous; $d_{\mathrm{S}}$ synonymous; $Z$ test $p$-values for rejecting the null hypothesis of neutrality $\left(d_{N}=d_{\mathrm{s}}\right)$ for the alternative hypotheses of non-neutrality $\left(d_{N} \neq d_{S}\right)$, positive selection $\left(d_{N}>d_{S}\right)$, and purifying selection $\left(d_{N}\right.$ $\left.<d_{\mathrm{s}}\right)$. 
1 Table 3 The Indices of selection at the $D Q A, D Q B, D R A$ and $D R B$ loci.

\begin{tabular}{|c|c|c|c|c|c|c|c|c|c|}
\hline Allele & Type & No. & aa distance & $d_{\mathrm{N}}$ & $d_{\mathrm{S}}$ & $d_{\mathrm{N}} / d_{\mathrm{S}}$ & Z; & $\mathrm{Z}$ & $\mathrm{Z}$ \\
\hline & & & & & & & $d_{\mathrm{N}} \neq d_{\mathrm{S}}$ & $d_{\mathrm{N}}>d_{\mathrm{S}}$ & $d_{\mathrm{N}}<d_{\mathrm{S}}$ \\
\hline \multirow[t]{3}{*}{$D Q A$} & All & 82 & $0.213 \pm 0.029$ & $0.138 \pm 0.024$ & $0.177 \pm 0.042$ & 0.779 & 0.296 & 1.000 & 0.143 \\
\hline & ABS & 21 & $0.416 \pm 0.066$ & $0.330 \pm 0.088$ & $0.287 \pm 0.110$ & 1.150 & 0.728 & 0.361 & 1.000 \\
\hline & non-ABS & 61 & $0.148 \pm 0.031$ & $0.086 \pm 0.021$ & $0.148 \pm 0.041$ & 0.581 & 0.123 & 1.000 & 0.061 \\
\hline \multirow[t]{3}{*}{$D Q B$} & All & 76 & $0.155 \pm 0.026$ & $0.097 \pm 0.018$ & $0.086 \pm 0.018$ & 1.127 & 0.621 & 0.322 & 1.000 \\
\hline & ABS & 19 & $0.264 \pm 0.071$ & $0.206 \pm 0.079$ & $0.133 \pm 0.076$ & 1.549 & 0.248 & 0.123 & 1.000 \\
\hline & non-ABS & 57 & $0.124 \pm 0.024$ & $0.068 \pm 0.014$ & $0.076 \pm 0019$ & 0.895 & 0.734 & 1.000 & 0.371 \\
\hline \multirow[t]{3}{*}{$D R A$} & All & 81 & $0.028 \pm 0.007$ & $0.014 \pm 0.004$ & $0.025 \pm 0.007$ & 0.560 & 0.138 & 1.000 & 0.069 \\
\hline & ABS & 20 & $0.042 \pm 0.019$ & $0.017 \pm 0.008$ & $0.028 \pm 0.022$ & 0.607 & 0.649 & 1.000 & 0.317 \\
\hline & non-ABS & 61 & $0.023 \pm 0.007$ & $0.013 \pm 0.004$ & $0.025 \pm 0.008$ & 0.520 & 0.133 & 1.000 & 0.077 \\
\hline \multirow[t]{3}{*}{$D R B$} & All & 79 & $0.212 \pm 0.028$ & $0.141 \pm 0.023$ & $0.114 \pm 0.025$ & 1.228 & 0.429 & 0.202 & 1.000 \\
\hline & ABS & 15 & $0.524 \pm 0.057$ & $0.594 \pm 0.132$ & $0.128 \pm 0.080$ & 4.640 & 0.001 & 0.001 & 1.000 \\
\hline & non-ABS & 64 & $0.144 \pm 0.025$ & $0.076 \pm 0.015$ & $0.112 \pm 0.029$ & 0.678 & 0.247 & 1.000 & 0.129 \\
\hline
\end{tabular}

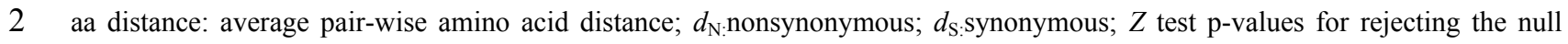

3 hypothesis of neutrality $\left(d_{\mathrm{N}}=d_{\mathrm{S}}\right)$ for the alternative hypotheses of non-neutrality $\left(d_{\mathrm{N}} \neq d_{\mathrm{S}}\right)$, positive selection $\left(d_{\mathrm{N}}>d_{\mathrm{S}}\right)$, and 4 purifying selection $\left(d_{\mathrm{N}}<d_{\mathrm{S}}\right)$. 


\section{Table 4 (on next page)}

Table 4 Estimation of codon evolution models for the ELA class II DQA, DQB, DRA and $D R B$ loci.

Note: $p=$ number of free parameters in the $\omega$ distribution; $\ln \mathrm{L}=\log$-likelihood; Model parameter estimates include the nonsynonymous to synonymous rate ratio $(\omega)$ and proportion of sites $(p)$ under each $\omega$ site class. Sites under selection were predicted by the Bayes Empirical Bayes (BEB) approach: sites inferred to be under positive selection with posterior probabilities $>99 \%$. 
Table 4 Estimation of codon evolution models for the ELA class II $D Q A, D Q B, D R A$ and $D R B$ loci.

\begin{tabular}{|c|c|c|c|c|c|}
\hline Locus & Nested model pairs & $\mathrm{p}$ & $\ln \mathrm{L}$ & Parameter estimates & Site under positive selection \\
\hline \multirow[t]{12}{*}{$D Q A$} & M0: one-ratio & 2 & -1411.41 & $\omega=1.002$ & NA \\
\hline & M3: discrete & 6 & -1286.74 & $\omega 0=0.000, \mathrm{p} 0=0.585$ & NA \\
\hline & & & & $\omega 1=0.283, \mathrm{p} 1=0.361$ & \\
\hline & & & & $\omega 2=6.020, \mathrm{p} 2=0.054$ & \\
\hline & M1a: nearly neutral & 3 & -1336.18 & $\omega 0=0.000, \mathrm{p} 0=0.851$ & NA \\
\hline & & & & $\omega 1=1.000, \mathrm{p} 1=0.149$ & \\
\hline & M2a: positive selection & 5 & -1281.72 & $\omega 0=0.000, \mathrm{p} 0=0.775$ & $10,17,18,30,46,51,60,61,65,69,70,72$ \\
\hline & & & & $\omega 1=1.000 \mathrm{pl}=0.205$ & \\
\hline & & & & $\omega 2=8.583, p 2=0.020$ & \\
\hline & M7: beta & 3 & -1338.52 & $\mathrm{p}=0.008, \mathrm{q}=0.054$ & \\
\hline & M8: beta\& $\omega$ & 5 & -1281.73 & $\mathrm{p} 0=0.979, \mathrm{p} 1=0.021$ & $10,17,18,30,46,51,52,60,61,65,68,69,70,72$ \\
\hline & & & & $\mathrm{p}=0.005, \mathrm{q}=0.020, \boldsymbol{\omega}=\mathbf{8 . 4 2 5}$ & \\
\hline \multirow[t]{12}{*}{$D Q B$} & M0: one-ratio & 2 & -1682.05 & $\omega=0.449$ & NA \\
\hline & M3: discrete & 6 & -1461.64 & $\omega 0=0.054, \mathrm{p} 0=0.921$ & NA \\
\hline & & & & $\omega 1=1.283, \mathrm{p} 1=0.073$ & \\
\hline & & & & $\omega 2=6.935, \mathrm{p} 2=0.006$ & \\
\hline & M1a: nearly neutral & 3 & -1508.29 & $\omega 0=0.025, \mathrm{p} 0=0.951$ & NA \\
\hline & & & & $\omega 1=1.000, \mathrm{p} 1=0.048$ & \\
\hline & M2a: positive selection & 5 & -1462.34 & $\omega 0=0.043, \mathrm{p} 0=0.913$ & $16,27,57,61$ \\
\hline & & & & $\omega 1=1.000, \mathrm{p} 1=0.081$ & \\
\hline & & & & $\omega 2=6.240, p 2=0.005$ & \\
\hline & M7: beta & 3 & -1519.53 & $\mathrm{p}=0.008, \quad \mathrm{q}=0.054$ & $16,27,47,57,61$ \\
\hline & M8: beta\& $\omega$ & 5 & -1467.39 & $\mathrm{p} 0=0.994, \mathrm{p} 1=0.005$ & \\
\hline & & & & $p=0.072, q=0.490, \omega=6.373$ & \\
\hline \multirow[t]{12}{*}{$D R A$} & M0: one-ratio & 2 & -632.76 & $\omega=0.778$ & NA \\
\hline & M3: discrete & 6 & -612.55 & $\omega 0=0.000, \mathrm{p} 0=0.924$ & NA \\
\hline & & & & $\omega 1=0.000, \mathrm{p} 1=0.010$ & \\
\hline & & & & $\omega 2=10.031, \mathrm{p} 2=0.066$ & \\
\hline & M1a: nearly neutral & 3 & -626.11 & $\omega 0=0.000, \mathrm{p} 0=0.687$ & NA \\
\hline & & & & $\omega 1=1.000, \mathrm{p} 1=0.313$ & \\
\hline & M2a: positive selection & 5 & -612.55 & $\omega 0=0.000, \mathrm{p} 0=0.934$ & $12,14,15,16,18,19,49,64,68$ \\
\hline & & & & $\omega 1=1.000 \mathrm{pl}=0.001$ & \\
\hline & & & & $\omega 2=10.286, p 2=0.065$ & \\
\hline & M7: beta & 3 & -627.68 & $\mathrm{p}=0.013, \mathrm{q}=0.020$ & $12,14,15,16,18,19,49,64,68$ \\
\hline & M8: beta\& $\omega$ & 5 & -612.54 & $\mathrm{p} 0=0.934, \mathrm{p} 1=0.065$ & \\
\hline & & & & $\mathrm{p}=0.005, \mathrm{q}=6.831, \boldsymbol{\omega}=\mathbf{1 0 . 3 2 3}$ & \\
\hline \multirow[t]{3}{*}{$D R B$} & M0: one-ratio & 2 & -1720.32 & $\omega=0.772$ & NA \\
\hline & M3: discrete & 6 & -1534.47 & $\omega 0=0.074, \mathrm{p} 0=0.854$ & NA \\
\hline & & & & $\omega 1=1.351, \mathrm{p} 1=0.131$ & \\
\hline
\end{tabular}




\begin{tabular}{|c|c|c|c|c|}
\hline & & & $\omega 2=6.823, \mathrm{p} 2=0.015$ & \\
\hline M1a: nearly neutral & 3 & -1580.21 & $\begin{array}{l}\omega 0=0.030, \mathrm{p} 0=0.913 \\
\omega 1=1.000, \mathrm{p} 1=0.087\end{array}$ & NA \\
\hline M2a: positive selection & 5 & -1535.16 & $\begin{array}{l}\omega 0=0.054, \mathrm{p} 0=0.827 \\
\omega 1=1.000 \mathrm{p} 1=0.158 \\
\omega 2=\mathbf{5 . 9 7 2}, \mathrm{p} 2=0.015\end{array}$ & $1,2,23,28,48,58,61,62,65,69,77$ \\
\hline M7: beta & 3 & -1583.97 & $\mathrm{p}=0.016, \mathrm{q}=0.104$ & $1,2,23,28,47,48,58,61,62,65,69,77$ \\
\hline M8: beta\& $\omega$ & 5 & -1536.75 & $\begin{array}{l}\mathrm{p} 0=0.984, \mathrm{p} 1=0.015 \\
\mathrm{p}=0.087, \mathrm{q}=0.328, \omega=\mathbf{5 . 9 6 1}\end{array}$ & \\
\hline
\end{tabular}

2 Note: $\mathrm{p}=$ number of free parameters in the $\omega$ distribution; $\ln \mathrm{L}=$ log-likelihood; Model parameter estimates include the 3 nonsynonymous to synonymous rate ratio $(\omega)$ and proportion of sites (p) under each $\omega$ site class. Sites under selection were 4 predicted by the Bayes Empirical Bayes (BEB) approach: sites inferred to be under positive selection with posterior probabilities $5>99 \%$. 